\title{
Investigating the role of polymorphisms in miR-146a, -149, and -196a2 in the development of gastric cancer
}

\author{
J.Y. Gu and L. Tu \\ Shanghai Jiao Tong University, Shanghai, China \\ Corresponding author: L. Tu \\ E-mail: lintustu@163.com \\ Genet. Mol. Res. 15 (2): gmr.15027839 \\ Received October 15, 2015 \\ Accepted January 14, 2016 \\ Published May 13, 2016 \\ DOI http://dx.doi.org/10.4238/gmr.15027839
}

Department of Gastrointestinal Surgery, Ren Ji Hospital, School of Medicine,

\begin{abstract}
Here, we performed a case-control study to investigate the role of miR-146a, miR-149, and miR-196a2 polymorphisms in the development of gastric cancer using a hospital-based case-control design. A total of 186 gastric cancer patients and 186 control subjects were enrolled from Ren Ji Hospital between January 2012 and October 2014. MicroRNAs miR-146a, miR-149, and miR-196a2 were genotyped by polymerase chain reaction coupled with restriction fragment length polymorphism. Univariate logistic regression analysis revealed that patients with gastric cancer were more likely to be infected with Helicobacter pylori [odds ratio $(\mathrm{OR})=1.68,95 \%$ confidence interval $(\mathrm{CI})=1.07-1.96]$. Conditional multiple logistic regression analysis revealed that the TT genotype of miR-196a2 was associated with an increased risk of gastric cancer compared to the $\mathrm{CC}$ genotype $(\mathrm{OR}=$ $2.40 ; 95 \% \mathrm{CI}=1.26-4.61)$. Moreover, patients carrying both the TC and TT genotypes of miR-196a2 were correlated with an elevated risk of gastric cancer compared to those expressing the $\mathrm{CC}$ genotype alone $(\mathrm{OR}=1.67,95 \% \mathrm{CI}=1.01-2.75 ; \mathrm{P}=0.03)$. In conclusion, the results of
\end{abstract}


our study indicated that the miR-196a2 polymorphism was associated with gastric cancer development.

Key words: miR-146a; miR-149; miR-196a2; Polymorphism; Gastric cancer

\section{INTRODUCTION}

Gastric cancer accounts for approximately $13 \%$ of all deaths each year, with an incidence that is second only to those of lung, breast, colorectal, and prostate cancers. This invasive cancer is the leading cause of death in the developed world, with more than $70 \%$ of cases (677,000 cases) being reported in developing countries (456,000 men, 221,000 women), and the second leading cause of death in the developing world (Jemal et al., 2011; IARC, 2012). Half the total number of gastric cancer patients have been registered in Eastern Asia, specifically China. Some genetic and environmental factors have been indicated to play a critical role in the development of gastric cancer in addition to Helicobacter pylori infection (Wu et al., 2005; Dong et al., 2008; McNamara and El-Omar, 2008). However, the precise etiology of this disease remains unclear. Many studies have reported that genetic factors, such as $A P E 1, X R C C 1, L M P 2, L M P 7, I L G F-1$, and $I L-17$, may be involved in the development of gastric cancer (Farahani et al., 2015; Jin et al., 2015; Long et al., 2015; Ma et al., 2015).

Previous studies have reported the role of miRNA in a variety of biological processes, including cell proliferation, differentiation, and apoptosis, by regulating approximately $60 \%$ of the human protein coding genes (Ambros, 2003; Esquela-Kerscher and Slack, 2006). SNPs in miRNA genes may affect the property of the respective miRNA. Three common variants of miR-146a, miR-149, and miR-196a2 (rs2910164, rs2292832, and rs11614913, respectively) have previously been implicated in the development of multiple types of cancers, including gastrointestinal cancer. Previous studies have also assessed the association between miR146a, miR-149, and miR-196a2 polymorphisms and the development of gastric cancer, with inconclusive results (Ma et al., 2013; Dikeakos et al., 2014; Xu et al., 2015). Here, we carried out a case-control study to investigate the role of polymorphisms in miR-146a, miR-149, and miR-196a2in the development of gastric cancer.

\section{MATERIAL AND METHODS}

\section{Subjects}

A hospital-based case-control design was used in this study. A total of 186 hospitalized gastric cancer patients were selected from Ren Ji Hospital between January 2012 and October 2014. Gastric cancer was newly diagnosed and confirmed in all patients by two pathologists. Patients with secondary or recurrent tumors were excluded from this study.

A total of 186 individuals were randomly selected from among subjects who received regular health examinations at the Ren Ji Hospital between January 2012 and October 2014 as controls. Individuals with any digestive diseases and tumors were excluded as controls.

The H. pylori infection status was assessed by the urea breath test. The demographic, lifestyle, and clinical characteristics of all patients and controls, such as age, gender, smoking status, drinking status, hypertension, diabetes, H. pylori infection, tumor size, and TNM stage, 
were collected from medical records. Written informed consent was obtained from all included patients and controls. The ethical approval of our study was in line with the standards of the Declaration of Helsinki.

\section{DNA extraction and genotyping}

Five milliliter of peripheral blood was taken from all patients and controls, and stored in EDTA tubes. DNA was extracted using the TIANamp Blood DNA Kit according to the manufacturer protocols (Tiangen, Beijing, China). miR-146a, miR-149, and miR-196a2 were genotyped by polymerase chain reaction (PCR) coupled with restriction fragment length polymorphism. The primers, lengths of digested fragments, and restriction enzymes of miR146a, miR-149, and miR-196a2 are summarized in Table 1. The PCR cycles were set as follows: a denaturing step at $95^{\circ} \mathrm{C}$ for 5 min, followed by 30 cycles of denaturation at $91^{\circ} \mathrm{C}$ for $60 \mathrm{~s}$, annealing at $62^{\circ} \mathrm{C}$ for $60 \mathrm{~s}$, and extension at $72^{\circ} \mathrm{C}$ for $60 \mathrm{~s}$, and a final extension at $72^{\circ} \mathrm{C}$ for $5 \mathrm{~min}$. The PCR products were confirmed by electrophoresing on a $3 \%$ agarose gel stained with ethidium bromide, and visualized under ultraviolet light.

Table 1. Primers, lengths of digested fragments, and restriction enzymes of miR-146a, miR-149, and miR-196a2.

\begin{tabular}{l|l|c}
\hline MicroRNA & Primers (5'-3') & Restriction enzymes \\
\hline miR-146a & CATGGGTTGTGTCAGTGTCAGAGCT (Forward) & SacI \\
& TGCCTTCTGTCTCCAGTCTTCCAA (Reverse) & $P v$ II \\
\hline miR-149 & TGTCTTCACTCCCGTGCTTGTCC (Forward) & $M s p I$ \\
\hline miR-196a2 & TGAGGCCCGAAACACCCGTA (Reverse) & \\
& CCCCTTCCCTTCTCCTCCAGATA (Forward) & \\
\hline
\end{tabular}

\section{Statistical analysis}

The relationship between demographic and lifestyle characteristics and gastric cancer risk were analyzed using univariate logistic regression analysis. A chi-square test with one degree of freedom was used to analyze the conformance of the genotype distributions of miR146a, miR-149, and miR-196a2 to the Hardy-Weinberg equilibrium (HWE). Conditional multiple logistic regression analysis was used to analyze the role of miR-146a, miR-149 and miR-196a2 gene polymorphisms in the development of gastric cancer; the results were expressed by odds ratios (ORs) and their related $95 \%$ confidence intervals (CIs). All statistical tests were two-tailed and P values less than 0.05 were considered statistically significant. SPSS v.16.0 (SPSS Inc., Chicago, IL, USA) was used to perform all statistical analyses.

\section{RESULTS}

The mean age of gastric cancer patients and control subjects were $62.43 \pm 10.52$ and $58.36 \pm 11.47$ years, respectively (Table 2$)$. There were $58(31.18 \%)$ female and $128(68.82 \%)$ male patients; the controls were gender-matched. Univariate logistic regression analysis revealed that patients with gastric cancer were more likely to be infected with $H$. pylori (OR $=1.68,95 \% \mathrm{CI}=1.07-1.96)$. Of the 186 patients, $72(38.71 \%)$ were at TNM stage I-II and 114 $(61.29 \%)$ were at stage III-IV; $84(45.16 \%)$ had a tumor size $\leq 5 \mathrm{~cm}$, while the tumor size of $102(54.84 \%)$ was $>5 \mathrm{~cm}$. 
Table 2. Demographic and lifestyle characteristics of gastric cancer patients and control subjects.

\begin{tabular}{|c|c|c|c|c|c|c|c|}
\hline Variables & Patients $(\mathrm{N}=186)$ & $\%$ & Controls $(\mathrm{N}=186)$ & $\%$ & $\chi^{2}$ test & OR $(95 \% \mathrm{CI})$ & $\mathrm{P}$ value \\
\hline Age (years) & $62.43 \pm 10.52$ & & $58.36 \pm 11.47$ & & & & \\
\hline \multicolumn{8}{|l|}{ Gender } \\
\hline Females & 58 & 31.18 & 85 & 45.70 & & 1.0 (Ref.) & - \\
\hline Males & 128 & 68.82 & 101 & 54.30 & 8.28 & $1.86(1.19-2.90)$ & 0.004 \\
\hline \multicolumn{8}{|c|}{ Smoking status } \\
\hline No & 124 & 66.67 & 133 & 71.51 & & 1.0 (Ref.) & - \\
\hline Yes & 62 & 33.33 & 53 & 28.49 & 1.02 & $1.25(0.79-2.00)$ & 0.31 \\
\hline \multicolumn{8}{|c|}{ Drinking status } \\
\hline No & 122 & 65.59 & 128 & 68.82 & & 1.0 (Ref.) & - \\
\hline Yes & 64 & 34.41 & 58 & 31.18 & 0.44 & $1.16(0.73-1.83)$ & 0.51 \\
\hline \multicolumn{8}{|c|}{ Hypertension } \\
\hline No & 72 & 38.71 & 89 & 47.85 & & 1.0 (Ref.) & - \\
\hline Yes & 114 & 61.29 & 97 & 52.15 & 3.16 & $1.45(0.94-2.24)$ & 0.08 \\
\hline \multicolumn{8}{|l|}{ Diabetes } \\
\hline No & 12 & 6.45 & 9 & 4.84 & & 1.0 (Ref.) & - \\
\hline Yes & 174 & 93.55 & 177 & 95.16 & 0.45 & $0.74(0.27-1.96)$ & 0.50 \\
\hline \multicolumn{8}{|c|}{ H. pylori infection } \\
\hline No & 109 & 58.60 & 131 & 70.43 & & 1.0 (Ref.) & - \\
\hline Yes & 77 & 41.40 & 55 & 29.57 & 5.68 & $1.68(1.07-2.65)$ & 0.02 \\
\hline \multicolumn{8}{|l|}{ TNM stage } \\
\hline I-II & 72 & 38.71 & & & & & \\
\hline III-IV & 114 & 61.29 & & & & & \\
\hline \multicolumn{8}{|c|}{ Tumor size $(\mathrm{cm})$} \\
\hline$\leq 5$ & 84 & 45.16 & & & & & \\
\hline$>5$ & 102 & 54.84 & & & & & \\
\hline
\end{tabular}

The genotype distributions of miR-146a, miR-149, and miR-196a2 polymorphisms are presented in Table 3. The genotype distributions of miR-146a, miR-149, and miR-196a2 in patients and controls did not deviate from the HWE (P values of polymorphisms in miR146a, miR-149, and miR-196a 2 in patients and controls were $0.80,0.60$, and 0.62 , and 0.64 , 0.47 , and 0.31 , respectively). The chi-square test revealed a significant difference between the genotype distribution of miR-196a 2 between gastric cancer patients and controls $\left(\chi^{2}=8.27\right.$, $\mathrm{P}=0.02)$; however, the distributions of miR-146a and miR-149 did not differ significantly.

Table 3. Genotype distributions of miR-146a, miR-149, and miR-196a2 polymorphisms between patients with gastric cancer and control subjects.

\begin{tabular}{l|c|c|c|c|c|c|c|c}
\hline SNP & Patients & $\%$ & Controls & $\%$ & Chi-square test & P value & \multicolumn{2}{|c}{ P value for HWE } \\
\cline { 5 - 9 } & & & & & & & & \\
\hline miR-146a & & & & & & & & \\
\hline GG & 66 & 35.48 & 70 & 37.63 & & & & \\
\hline GC & 91 & 48.92 & 90 & 48.39 & & & & \\
\hline CC & 29 & 15.59 & 25 & 13.44 & 0.42 & 0.81 & 0.80 & 0.64 \\
\hline miR-149 & & & & & & & & \\
\hline CC & 55 & 29.57 & 60 & 32.26 & & & & \\
\hline TC & 89 & 47.85 & 87 & 46.77 & & & & \\
\hline TT & 42 & 22.58 & 39 & 20.97 & 0.35 & 0.84 & 0.60 & 0.47 \\
\hline miR-196a2 & & & & & & & & \\
\hline CC & 39 & 20.97 & 57 & 30.65 & & & & \\
\hline TC & 96 & 51.61 & 98 & 52.69 & & & & \\
\hline TT & 51 & 27.42 & 31 & 16.67 & 8.27 & 0.02 & 0.62 & 0.31 \\
\hline
\end{tabular}

HWE $=$ Hardy-Weinberg equilibrium.

Conditional multiple logistic regression analysis indicated that the TT genotype of miR-196a2 was associated with an increased risk of gastric cancer compared to the CC 
genotype $(\mathrm{OR}=2.40 ; 95 \% \mathrm{CI}=1.26-4.61$; Table 4$)$. Moreover, patients carrying both the TC and TT genotype of miR-196a 2 were correlated with an elevated risk of gastric cancer, compared to those carrying only the $\mathrm{CC}$ genotype $(\mathrm{OR}=1.67,95 \% \mathrm{CI}=1.01-2.75 ; \mathrm{P}=0.03)$. However, we did not find any significant association between the miR-146a and miR-149 polymorphisms and the development of gastric cancer.

Table 4. Association between miR-146a, miR-149, and miR-196a2 polymorphisms and risk of gastric cancer.

\begin{tabular}{l|c|c|c|c|c|c}
\hline SNP & Cases & $\%$ & Controls & $\%$ & ${\text { OR }(95 \% \text { CI })^{1}}^{\text {P value }}$ \\
\hline miR-146a & & & & & & \\
\hline GG & 66 & 35.48 & 70 & 37.63 & $1.0($ Ref.) & - \\
\hline GC & 91 & 48.92 & 90 & 48.39 & $1.07(0.67-1.72)$ & 0.76 \\
\hline CC & 29 & 15.59 & 25 & 13.44 & $1.23(0.62-2.43)$ & 0.52 \\
\hline GC+CC & 120 & 64.51 & 115 & 61.83 & $1.11(0.71-1.73)$ & 0.64 \\
\hline miR-149 & & & & & & \\
\hline CC & 55 & 29.57 & 60 & 32.26 & $1.0($ Ref.) & - \\
\hline TC & 89 & 47.85 & 87 & 46.77 & $1.12(0.68-1.84)$ & 0.65 \\
\hline TT & 42 & 22.58 & 39 & 20.97 & $1.17(0.64-2.16)$ & 0.58 \\
\hline TC+TT & 131 & 70.43 & 126 & 67.74 & $1.13(0.71-1.80)$ & 0.57 \\
\hline CC & 39 & & & & & \\
\hline TC & 96 & 20.97 & 57 & 30.65 & $1.0(\operatorname{Ref})$. & - \\
\hline TT & 51 & 27.42 & 31 & 16.67 & $2.40(1.26-4.61)$ & 0.004 \\
\hline TC+TT & 147 & 79.03 & 129 & 69.36 & $1.67(1.01-2.75)$ & 0.03 \\
\hline
\end{tabular}

${ }^{1}$ Adjusted for age, gender, and Helicobacter pylori infection. $\mathrm{OR}=$ odds ratio; $\mathrm{CI}=$ confidence interval.

\section{DISCUSSION}

In this case-control study conducted in the Chinese population, we explored the role of polymorphisms in the microRNA miR-146a, miR-149, and miR-196a2 in gastric cancer susceptibility. The TT and TC+TT genotypes of miR-196a 2 were found to be associated with an increased risk of gastric cancer compared to the CC genotype; however, no significant associations were found between miR-146a and miR-149 polymorphisms and gastric cancer risk.

Several previous studies have investigated the role of miR-196a2 polymorphisms in the development of several types of human cancers, such as lung cancer, colorectal cancer, breast cancer, hepatocellular carcinoma, and non-Hodgkin lymphoma (Hoffman et al., 2009; Parlayan et al., 2014; Peng et al., 2014; Li et al., 2015; Qi et al., 2015; Sodhi et al., 2015). $\mathrm{Li}$ et al. (2015) discovered that the miR-196a2 polymorphism could increase the risk of nonHodgkin lymphoma by changing the expression of mature miR-196a in a Chinese population. Peng et al. (2014), in a meta-analysis comprising of 12 studies, reported a correlation between themiR-196a2 polymorphism and the development of HCC. Qi et al. (2015), in a casecontrol study with 321 breast cancer patients and 290 controls, suggested that the miR-196a2 polymorphism could predict breast cancer risk in the Chinese population.

So far, several studies have reported an association between the miR-196a2 polymorphism and development of gastric cancer, but with inconclusive results (Okubo et al., 2010; Ma et al., 2013; Dikeakos et al., 2014; Wei et al., 2015; Xu et al., 2015). Three studies reported a positive association between miR-196a2 polymorphism and susceptibility to gastric cancer (Ma et al., 2013; Dikeakos et al., 2014; Wei et al., 2015), while Okubo et al. (2010) did not. Wei et al. (2015), in a meta-analysis comprising eight case-control studies, reported that the miR-196a2 polymorphism could influence the development of gastric cancer.

There are three limitations in the present study. First, the patients and control subjects 
were selected from only one hospital, which may bring in selection bias. However, the genetic distributions of the three SNPs were in agreement with the HWE, and thus the sample had representative of the general population. Second, some gene-gene interaction may influence the development of gastric cancer. Third, the sample size is relatively small, which may reduce the statistical power to find difference between groups.

In conclusion, our study indicated that the miR-196a 2 polymorphism was associated with gastric cancer development, which can be used as the predictive biomarker for the susceptibility to gastric cancer. Further studies are required to validate our study findings.

\section{Conflicts of interest}

The authors declare no conflict of interest.

\section{ACKNOWLEDGMENTS}

Research supported by grants provided by the National Natural Science Foundation of China (\#81272743) and the Shanghai Committee of Science and Technology (\#13411950902).

\section{REFERENCES}

Ambros V (2003). MicroRNA pathways in flies and worms: growth, death, fat, stress, and timing. Cell 113: 673-676. http://dx.doi.org/10.1016/S0092-8674(03)00428-8

Dikeakos P, Theodoropoulos G, Rizos S, Tzanakis N, et al. (2014). Association of the miR-146aC $>$ G, miR-149T $>C$, and miR-196a2T $>$ C polymorphisms with gastric cancer risk and survival in the Greek population. Mol. Biol. Rep. 41: 1075-1080. http://dx.doi.org/10.1007/s11033-013-2953-0

Dong LM, Potter JD, White E, Ulrich CM, et al. (2008). Genetic susceptibility to cancer: the role of polymorphisms in candidate genes. JAMA 299: 2423-2436. http://dx.doi.org/10.1001/jama.299.20.2423

Esquela-Kerscher A and Slack FJ (2006). Oncomirs - microRNAs with a role in cancer. Nat. Rev. Cancer 6: 259-269. http://dx.doi.org/10.1038/nrc1840

Farahani RK, Azimzadeh P, Rostami E, Malekpour H, et al. (2015). Evaluation of insulin like growth facror-1 genetic polymorphism with gastric cancer susceptibility and clinicopathological features. Asian Pac. J. Cancer Prev. 16: 4215-4218. http://dx.doi.org/10.7314/APJCP.2015.16.10.4215

Hoffman AE, Zheng T, Yi C, Leaderer D, et al. (2009). microRNA miR-196a-2 and breast cancer: a genetic and epigenetic association study and functional analysis. Cancer Res. 69: 5970-5977. http://dx.doi.org/10.1158/0008-5472.CAN$\underline{09-0236}$

International Agency for Research on Cancer (2012). Stomach Cancer. Estimated Incidence, Mortality and Prevalence Worldwide in 2012. http://globocan.iarc.fr/Pages/fact_sheets_cancer.aspx. Accessed October 10, 2015.

Jemal A, Bray F, Center MM, Ferlay J, et al. (2011). Global cancer statistics. CA Cancer J. Clin. 61: 69-90. http://dx.doi. org/10.3322/caac. 20107

Jin EH, Kim J, Lee SI and Hong JH (2015). Association between polymorphisms in APE1 and XRCC1 and the risk of gastric cancer in Korean population. Int. J. Clin. Exp. Med. 8: 11484-11489.

Li T, Niu L, Wu L, Gao X, et al. (2015). A functional polymorphism in microRNA-196a2 is associated with increased susceptibility to non-Hodgkin lymphoma. Tumour Biol. 36: 3279-3284. http://dx.doi.org/10.1007/s13277-014$\underline{2957-y}$

Long ZW, Yu HM, Wang YN, Liu D, et al. (2015). Association of IL-17 polymorphisms with gastric cancer risk in Asian populations. World J. Gastroenterol. 21: 5707-5718. http://dx.doi.org/10.3748/wjg.v21.i18.5707

Ma X, Yang C, Tang R, Xu Z, et al. (2015). Association between LMP2 and LMP7 gene polymorphisms and the risk of gastric cancer: A case-control study. Oncol. Lett. 10: 509-517.

Ma XP, Zhang T, Peng B, Yu L, et al. (2013). Association between microRNA polymorphisms and cancer risk based on the findings of 66 case-control studies. PLoS One 8: e79584. http://dx.doi.org/10.1371/journal.pone.0079584

McNamara D and El-Omar E (2008). Helicobacter pylori infection and the pathogenesis of gastric cancer: a paradigm for host-bacterial interactions. Dig. Liver Dis. 40: 504-509. http://dx.doi.org/10.1016/j.dld.2008.02.031 
Okubo M, Tahara T, Shibata T, Yamashita H, et al. (2010). Association between common genetic variants in premicroRNAs and gastric cancer risk in Japanese population. Helicobacter 15: 524-531. http://dx.doi.org/10.1111/ j.1523-5378.2010.00806.x

Parlayan C, Ikeda S, Sato N, Sawabe M, et al. (2014). Association analysis of single nucleotide polymorphisms in miR146a and miR-196a2 on the prevalence of cancer in elderly Japanese: a case-control study. Asian Pac. J. Cancer Prev. 15: 2101-2107.http://dx.doi.org/10.7314/APJCP.2014.15.5.2101

Peng Q, Li S, Lao X, Chen Z, et al. (2014). The association of common functional polymorphisms in mir-146a and mir196a2 and hepatocellular carcinoma risk: evidence from a meta-analysis. Medicine (Baltimore) 93: e252. http:// dx.doi.org/10.1097/MD.0000000000000252

Qi P, Wang L, Zhou B, Yao WJ, et al. (2015). Associations of miRNA polymorphisms and expression levels with breast cancer risk in the Chinese population. Genet. Mol. Res. 14: 6289-6296. http://dx.doi.org/10.4238/2015.June.11.2

Sodhi KK, Bahl C, Singh N, Behera D, et al. (2015). Functional genetic variants in pre-miR-146a and 196a2 genes are associated with risk of lung cancer in North Indians. Future Oncol. 11: 2159-2173. http://dx.doi.org/10.2217/ fon. 15.143

Wei Y, Li L and Gao J (2015). The association between two common polymorphisms (miR-146a rs2910164 and miR196a2 rs11614913) and susceptibility to gastric cancer: A meta-analysis. Cancer Biomark. 15: 235-248. http://dx.doi. org/10.3233/CBM-150470

Wu MS, Chen CJ and Lin JT (2005). Host-environment interactions: their impact on progression from gastric inflammation to carcinogenesis and on development of new approaches to prevent and treat gastric cancer. Cancer Epidemiol. Biomarkers Prev. 14: 1878-1882.http://dx.doi.org/10.1158/1055-9965.EPI-04-0792

Xu Q, Liu JW and Yuan Y (2015). Comprehensive assessment of the association between miRNA polymorphisms and gastric cancer risk. Mutat. Res. Rev. Mutat. Res. 763: 148-160. http://dx.doi.org/10.1016/j.mrrev.2014.09.004 